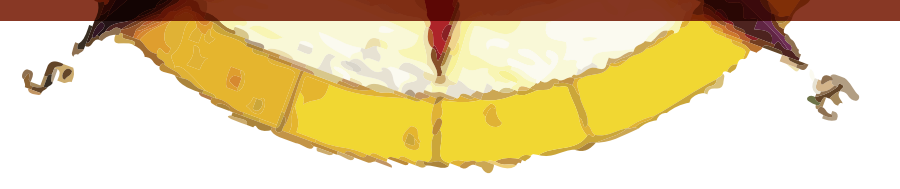

\title{
REPRESENTACIONES ESPACIALES ELABORADAS POR ESCOLARES DE LA ESCUELA RURAL DE EL MOLLE, VALLE DEL RÍO ELQUI, CHILE $^{1}$
}

\author{
Carmen Varela Araya ${ }^{2}$
}

\section{RESUMEN}

Este artículo presenta percepciones acerca de la identidad personal y del espacio cotidiano en los que viven escolares de una escuela rural localizada en el Valle de Elqui, región de Coquimbo, Chile. Mediante mapas mentales se obtiene como resultado generalizado el agrado o desagrado que les significa vivir en contacto con la naturaleza de su entorno geográfico observado y vivido mediante los diarios desplazamientos residencia - escuela; la satisfacción o rechazo de pertenecer al lugar de su residencia y el grado de convivencia armónica con familiares y la comunidad.

Palabras clave: representaciones espaciales, mapas mentales, identidad, autoestima escolar y entorno geográfico

\begin{abstract}
This article presents the perceptions about personal identity and the everyday space in school living a rural school located in the Elqui Valley, Coquimbo Region, Chile. Obtained using mind maps as a result is generalized like or dislike them means to live in contact with nature in their geographical area; observed and lived through the daily displacements residence - school, the satisfaction or rejection of belonging to the place of residence and the degree with the harmonious coexistence of community.
\end{abstract}

Keywords: spatial representations, mind maps, personal identity, school self-esteem, geographical environment

\footnotetext{
1 Sinceros agradecimientos a los escolares participantes de III y IV Nivel Básico, al personal docente y paradocentes de la Escuela Dagoberto Campos y especialmente al Sr. Director Don Gabriel Pastén Tapia por la disposición y colaboración prestada a la realización de estas actividades.
} 


\section{RESUMO}

Este artigo a presenta percepções a respeito da identidade pessoal e do espaço quotidiano em que vive escolares de uma escola rural localizada no Vale de Elqui, região de Coquimbo, Chile. Mediante mapas mentais obtém-se como resultado generalizado o agrado ou desagrado que lhes significa viver em contato com a naturalde seu meio geográfico observado e vivido mediante as diárias deslocações residência - escola; a satisfação ou rejeição de pertencer ao lugar de sua residência e o grau de convivência harmônica com familiares e a comunidade.

Palavras-chave: representações espaciais, mapas mentais, identidade pessoal, autoestima escolar, meio geográfico.

\section{PRESENTACIÓN}

La escuela rural de El Molle "Dagoberto Campos Nuñez" se encuentra localizada en la comuna de Vicuña (centrada en $29^{\circ} 58^{\prime}$ Latitud Sur y $70^{\circ} 58^{\prime}$ longitud W.)perteneciente administrativamente a la provincia de Elqui, región de Coquimbo, según el sistema vigente en la organización regional de Chile.

El citado establecimiento se asienta en el pequeño y antiguo pueblo de El Molle (210 habitantes; INE, 2002), actualmente se conecta a la ruta 41; conocida como circuito Gabriela Mistral, en homenaje a la poetisa chilena galardonada con premio Nobel de Literatura 1945 y originaria de esta área geográfica vinculada al Valle del río Elqui, uno de los valles fluviales que caracterizan a la Región de Coquimbo ubicada en le centro - norte chileno. (Ver Fig.1)
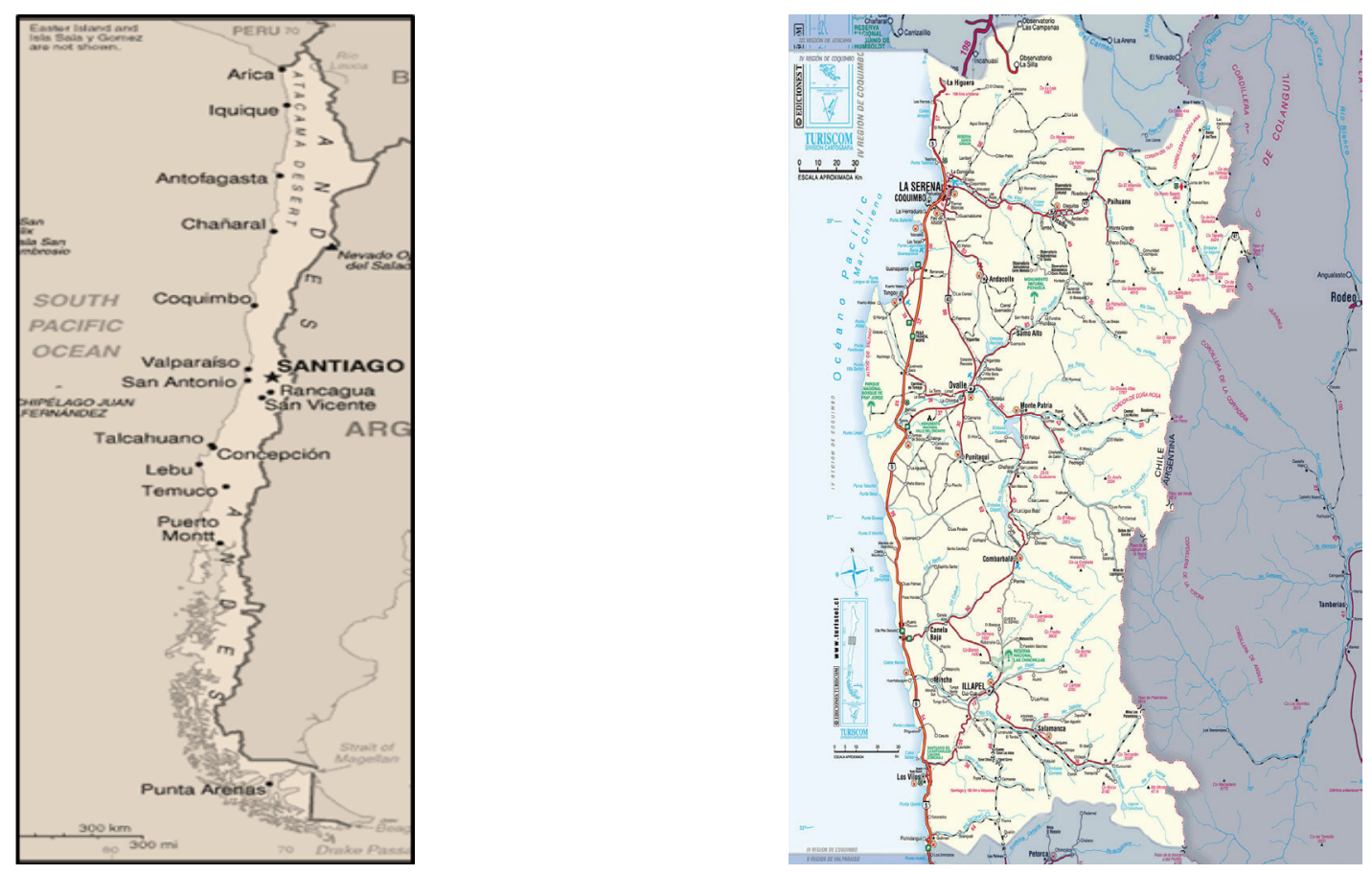

Figura.1. Localización del Valle del Río Elqui, Región de Coquimbo, Chile.

Fuente: Mapa Rutero, Turistel, 2012 
El Molle distante 32 kilómetros de la Ciudad de La Serena (capital de la región de Coquimbo;(147.815 habitantes, INE, 2002) es uno de los pequeños asentamientos que mantiene una dinámica permanente de flujos poblacionales con la ciudad primada serenense destinados al abastecimiento de diversos bienes y servicios, principalmente comercio al por mayor; asistencia judicial, especializaciones médicas y educación superior. (Varela,2011).

Por otra parte, la ciudad de Vicuña, capital de la comuna del mismo nombre (24.010 habitantes; INE, 2002) distante 28 kilómetros de El Molle, recibe cotidianamente demandas de este poblado para el comercio al detalle, asistencia bancaria y atención primaria de salud más educación secundaria, entre otras menos especializadas. (Varela, 2011).

La posición intermedia de El Molle con respecto al sistema de asentamientos del valle elquino es beneficiado con la dinámica de flujos relacionados con la actividad agrícola (se cultiva viñedos, paltos, papayos, nogales, almendros); turísticos (principalmente atractivos astronómicos); y recreativos, relacionados con existencia de diversos camping y restaurantes. (Ver Fig.2).

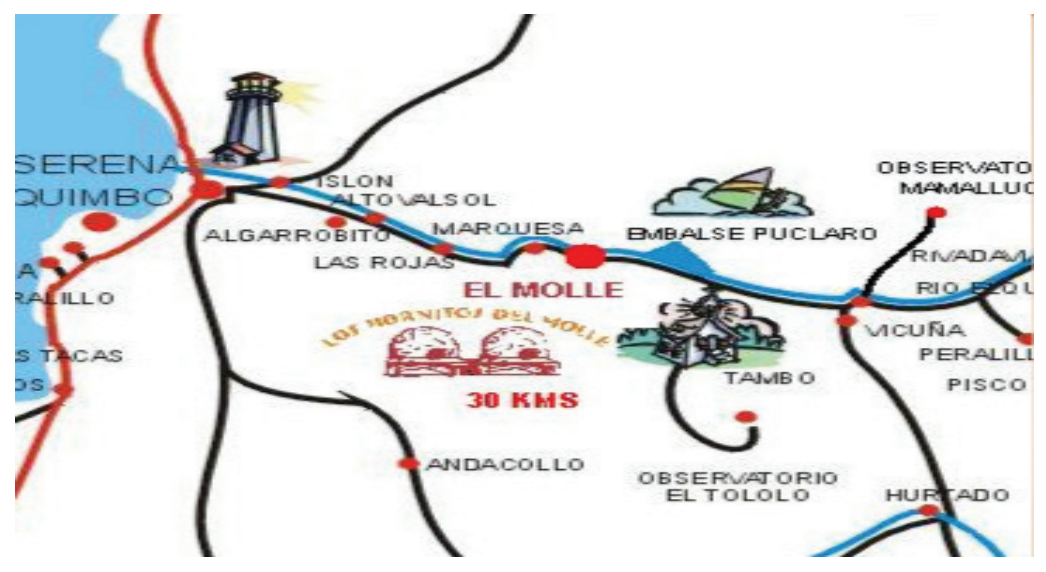

Figura.2 Mapa pictórico de ruta al pueblo de El Molle y entorno turístico. Fuente: Turistel Chile; 2012

Se estima que las actividades se dinamizarán a futuro con la consolidación del proyecto Túnel Paso Agua Negra ( conexión principal con la provincia de San Juan; Argentina y otros; Ver http:// www.ebitan.org/ebitan/).

Normalmente estos flujos a través del valle ocasionan según las características y periocidad de las actividades económicas existentes, una población residente y otra flotante en el citado pueblo y otros menores localizados en su entorno.

En este contexto locacional se encuentra la Escuela Rural Dagoberto Campos; el establecimiento cuenta con un total de 157 alumnos, distribuidos en niveles de $1^{\circ}$ a $8^{\circ}$ Básico y 15 profesores, la mayor parte residente en la ciudad de La Serena y puerto de Coquimbo, estos realizan viajes diarios entre las dos localidades para cumplir con la labor docente. El establecimiento escolar presenta la singularidad de tener una gran diversidad en la estructura escolar en cuanto a procedencia geográfica; condición socioeconómica y étnica, entre otras. 
Es necesario destacar que el 64\% del alumnado proceden de caseríos y pueblitos ubicados en el entorno y recorren diariamente distancias entre 6 y 12 kilómetros, lo que necesariamente requiere de un par de buses para el traslado, financiado uno de ellos por el Municipio y otro por los apoderados de los escolares; ambos siguen el mismo itinerario.

La Tabla $\mathrm{N}^{\circ} 1$ adjunta indica los lugares de procedencia geográfica de los escolares por niveles de enseñanza y sexo, según datos entregados por la Dirección del establecimiento de escolares matriculados al mes de Abril, 2013.

Dirección Establecimiento, 2013.

\begin{tabular}{|c|c|c|c|c|c|c|c|c|c|c|c|c|c|c|c|c|c|c|c|c|c|c|c|c|}
\hline \multirow{3}{*}{$\begin{array}{l}\text { Lugares } \\
\text { La Serena }\end{array}$} & \multicolumn{4}{|c|}{ N. T } & \multicolumn{2}{|c|}{$1^{\mathrm{a}}$} & \multicolumn{2}{|l|}{$2^{\circ}$} & \multicolumn{2}{|l|}{$3^{\circ}$} & \multicolumn{2}{|l|}{$4^{\circ}$} & \multicolumn{2}{|l|}{$5^{\circ}$} & \multicolumn{2}{|l|}{$6^{\circ}$} & \multicolumn{2}{|l|}{$7^{\circ}$} & \multicolumn{2}{|l|}{$8^{\circ}$} & \multicolumn{3}{|c|}{ TOTAL } & \multirow[b]{2}{*}{ \% } \\
\hline & $1^{\circ}$ & & $2^{\circ}$ & & $\mathrm{H}$ & M & $\mathrm{H}$ & M & $\mathrm{H}$ & $\mathrm{M}$ & $\mathrm{H}$ & $\mathrm{M}$ & $\mathrm{H}$ & $\mathrm{M}$ & $\mathrm{H}$ & $\mathrm{M}$ & $\mathrm{H}$ & $\mathrm{M}$ & $\mathrm{H}$ & M & $\mathrm{H}$ & $\mathrm{M}$ & $\mathrm{T}$ & \\
\hline & & & & & & & & & & & & & & & 1 & & & & & & 1 & & & $\underline{0.7}$ \\
\hline Pelícana & & & 1 & & & 1 & 1 & & & & 1 & & 1 & 2 & & 1 & & 1 & 1 & & 5 & 5 & 10 & $\underline{6.6}$ \\
\hline El Arrayán & & & 1 & 2 & 1 & & & 1 & & 1 & 1 & & 1 & 4 & & 1 & 1 & 1 & & 1 & 5 & 11 & 16 & $\underline{10.5}$ \\
\hline La Calera & & & & & 3 & & 2 & 1 & 1 & 6 & & & 4 & 4 & 1 & 1 & 7 & 5 & 1 & 6 & 19 & 23 & 42 & $\underline{27.6}$ \\
\hline Marquesa & & & & 1 & & 1 & 1 & & & 2 & & & & 2 & 3 & 1 & 3 & 2 & & & 7 & 9 & 16 & $\underline{10.5}$ \\
\hline $\begin{array}{l}\text { Nva. } \\
\text { Talcuna } \\
\end{array}$ & & & & & & & & & & & & & & & & & 1 & 1 & & & 1 & 1 & 2 & $\underline{1.3}$ \\
\hline E1 Molle & 3 & 1 & 4 & 7 & 2 & 2 & 2 & 1 & 2 & 2 & 4 & 2 & 2 & 3 & 1 & 7 & 1 & 3 & & 6 & 21 & 34 & 55 & $\underline{36.2}$ \\
\hline El Maitén & & & 1 & 1 & 1 & & 1 & & 1 & & & & & & & & & & & & 4 & 1 & 5 & $\underline{3.3}$ \\
\hline Almendral & 1 & & & & & & & & & & & & & & & & & & & & 1 & & 1 & $\underline{0.7}$ \\
\hline $\begin{array}{l}\text { Villa } \\
\text { Puclaro }\end{array}$ & & & & & & & & & & & & & 1 & & & & & & & 1 & 1 & 1 & 2 & $\underline{1.3}$ \\
\hline Vicuña & & & & & & & & & & & & & & & & & & & 1 & 1 & 1 & 1 & 2 & $\underline{1.3}$ \\
\hline TOTALES & 4 & 1 & 7 & 11 & 7 & 4 & 7 & 3 & 4 & 11 & 6 & 2 & 9 & 15 & 6 & 11 & 13 & 13 & 3 & 15 & 66 & 86 & 152 & \\
\hline
\end{tabular}

Tabla $N^{\circ} 1$. Lugar de Residencia de los Alumnos Matriculados por Sexo y Niveles.

Como se demuestra en la Tabla $\mathrm{N}^{\mathrm{o}} 1$ el $36.2 \%$ de los escolares viven en El Molle, el resto tiene como residencia pueblos vecinos, destacándose los procedentes de caseríos como La Calera (27.6\%). El Arrayán y Marquesa (con un aporte de $10.5 \%$ cada uno).Si bien, estas localidades disponen de escuelas, son unidocentes, atienden niveles de $1^{\circ}$ a $6^{\circ}$ Básico; situación que permite el desplazamiento diario de estudiantes a la Escuela Dagoberto Campos que es multidocente, según categorizaciones del sistema educativo rural chileno.

Este comportamiento de estructura escolar con desplazamiento espacial y diversidad socioeconómica justifica la elección del establecimiento como adecuado para la realización de talleres pedagógicos de identidad y percepción.

Cabe señalar que la diversidad socioeconómica se refleja en la distribución de la actividad realizada por padres y tutores (Ver Gráfico $\mathrm{N}^{\circ} 1$ ) y la categorización por renta percibida por estos (Ver Tabla $\mathrm{N}^{\mathrm{o}}$ 2). 


\section{Distribucion de las actividades de los padres o tutores de los escolares \%}

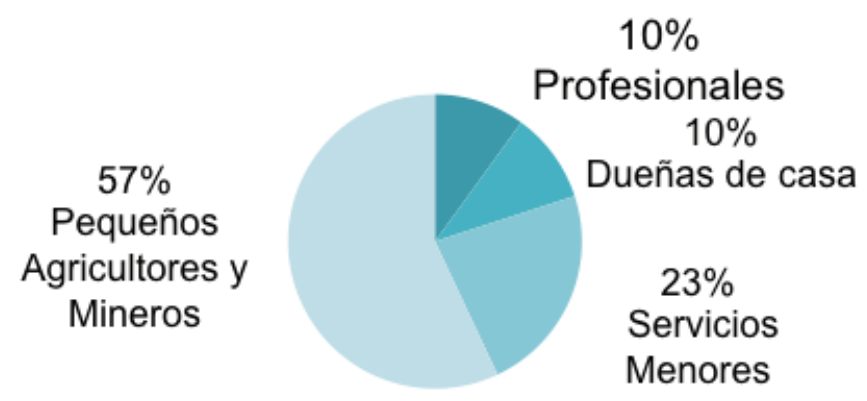

Gráfico $\mathrm{N}^{\mathrm{o}}$ 1.Distribución de las actividades de los padres o tutores. Fuente: Elaboración propia; 2013.

Es interesante considerar según la gráfica que la mayor parte de los padres y tutores de los escolares de la escuela se relacionan con las actividades representativas de este valle: pequeños agricultores o dependientes de viñedos y frutales, como así, pirquineros asociados a la pequeña minería informal. Según los resultados obtenidos de las percepciones escolares un $75 \%$ de ellas, es factible asociarla a los trabajos y espacio geográfico vivido por sus progenitores o familiares.

Por otra parte, la diferenciación de actividades distingue que existe un 10\% de profesionales, como de igual manera un $10 \%$ de dueñas de casa, situación que permite inferir mediante los dibujos el grado de admiración por el padre profesional o la madre dueña de casa.

La tabla $\mathrm{N}^{\mathrm{o}} 2$ presenta la variedad promedio de ingresos que perciben los padres y tutores clasificados en categorías por el establecimiento, lo que permite una observar la diferencia socioeconómica de los escolares, asociada a la actividad realizada por él /ella jefes de hogar.

\begin{tabular}{|c|c|c|c|c|}
\hline La situación es ... & & & & \\
\hline $\begin{array}{l}\text { Dólar USA }=518 \text { promedio pesos chilenos. } \\
(\text { Noviembre, 2013) }\end{array}$ & Pre-Básica & Básica & $\underline{\text { Total }}$ & $\%$ \\
\hline TRAMO 0: Sin Ingresos: & $\underline{03}$ & $\underline{05}$ & $\underline{08}$ & $\underline{05}$ \\
\hline TRAMO 1: Ingresos menores a $\$ 112.098$ & $\underline{01}$ & $\underline{08}$ & $\underline{09}$ & $\underline{06}$ \\
\hline TRAMO 2: Ingresos entre $\$ 112.099$ y $\$ 226.519$ & $\underline{06}$ & 41 & $\underline{47}$ & $\underline{31}$ \\
\hline TRAMO 3: Ingresos entre $\$ 226.520$ y $\$ 353.292$ & $\underline{08}$ & $\underline{52}$ & $\underline{60}$ & $\underline{40}$ \\
\hline TRAMO 4: Ingresos entre \$ 353.293 y \$ más & $\underline{05}$ & $\underline{23}$ & $\underline{28}$ & 18 \\
\hline
\end{tabular}

Tabla N ${ }^{\circ}$ 2. Distribución de Ingresos Familiares de los Escolares. Fuente. Datos Establecimiento ,2013 


\section{BREVE MARCO CONCEPTUAL Y TEÓRICO}

Una de las tendencias geográficas actuales, aún vigente, en ámbitos educativos en Chile es la Geografía de la Percepción y del Comportamiento basada en la aplicación de procedimientos e instrumentos cualitativosde Aprendizaje en Aula.Si bien cada persona percibe el espacio de modo único, el proceso de sociabilización determina que ciertos aspectos de las imágenes mentales sean compartidos por grandes grupos, como son por ejemplo, los grupos escolares.

Según Souto (2007, p.11 ) La Educación Geográfica permite construir una ciudadanía crítica,al menos en dos ámbitos fundamentales: en el estudio de las percepciones sociales y espaciales.

Horacio Capel (1973), considerado uno de los principales representantes clásicos de la Geografía de la Percepción concibe la región como espacio percibido.Esta corriente disciplinaria geográfica la fundamenta en el conductismo filosófico con fuerte vinculación a la Psicología. "A través de la percepción se descubre el paisaje, las imágenes espaciales y la conciencia territorial y regional; en definitiva será el espacio vivido e interiorizado el que prevalezca" (Capel,1981,p.62).

Según Antonio Zárate M.(1991,) la Geografía de la percepción o de las representaciones mentales ofrece posibilidades privilegiadas para un aprendizaje significativo de esta, al tener presente la estructura cognitiva, la diversidad y el desarrollo mental del estudiante.

Por otra parte, Lynch, K (1960) define percepción como "la sensación interior resultante de una impresión material hecha en los sentidos". Son los sentidos canales que permiten la gestación de la imagen; "Cada grupo humano tiene una percepción propia del espacio que ocupa, y de una forma u otra le pertenece" en Dollfus (1990,p.15).

Para Zamorano M.(1991,p.124) "el hombre percibe la realidad de un modo subjetivo; sus sistemas perceptivos (visual, auditivo, táctil, olfativo) le permite recibir la información que el medio le transmite permanentemente, la cual se traduce en una imagen que lleva el sello de los factores culturales y psicológicos de cada receptor".

Según Caneto, C (2002) es importante para los escolares comenzar por escalas espaciales como es el espacio que para ellos es el conocido y familiar. No debe obviarse, que el entorno familiar tiene una relación directa con aspectos del desarrollo personal del sujeto, lo que conlleva a un factible análisis de las potencialidades de cada individuo en la comprensión del entorno geográfico y el marco social en que desarrolla su vida.

De igual manera Carrasquel y Ugarte, (2012 .p.3) señalan "Ya desde la infancia, cada niño, como individuo que es, mira y vive de manera única; pareciera que su corta experiencia le va dejando espacio para imaginar gracias a lo cual va armando su propia versión de lo que ve y siente."

Los mismos autores indican basándose en conceptos vertidos por Machón (2009) acerca del dibujo (mapa mental) como un gráfico reproducido en un plano bidimensional que representan las imágenes derivadas de la percepción visual como combinaciones de diferentes formas que se producen en la mente del sujeto. En una primera fase son gestos gráficos precarios (garabatos) que se preparan para el dibujo y que deben considerarse como un periodo con características particulares asociadas al desarrollo cognitivo y biológico del niño. De igual manera, la identidad del yo se constru- 
ye, es un conocimiento que nace y que se refuerza con el tiempo transcurrido mediante continuas experiencias que acrecientan infinitamente el conocimiento de sí mismo.

Finalmente se cita textualmente a Lowenfeld y Brittain (2008, p39) "Sólo a través de la identificación con nosotros mismos podremos llegar a identificarnos con otros. Cuando un niño se identifica con su propio trabajo, cuando aprende a entender y a apreciar el ambiente que lo rodea, compenetrándose con él, desarrolla la actitud imprescindible para comprender las necesidades del prójimo". El proceso de creación involucra la incorporación del yo a la actividad; el propio acto de crear proporciona la comprensión del proceso que otros atraviesan al enfrentar sus propias experiencias".

Con base a estas consideraciones teóricas y otras motivadoras acerca de la identidad y autoestima se plantean los objetivos generales de los talleres realizados en la escuela de El Molle. Cabe señalar que estos talleres pedagógicos corresponden a una fase exploratoria y se aplica a una muestra de escolares del establecimiento que se detalla en un siguiente párrafo.

\section{Objetivos Generales del Taller de Identidad y Percepción.}

- Determinar mediante representaciones de mapa mentales y rótulos escritos acerca del conocimiento de sí mismo y del entorno social en que conviven cotidianamente: Familia y Escuela.

- Conocer mediante representaciones espaciales mentales lo que agrada o desagrada del lugar en que se vive y estudia.

- Detectar la capacidad de observación de los lugares que conforman el entorno geográfico de la residencia y del establecimiento escolar.

Para concretar estos objetivos el Taller se realiza actividades que estimulan la autoestima del escolar. Se ha establecido que el trabajo de auto estimación desarrolla una mayor confianza en los estudiantes y constituye una herramienta fundamental para manejar la discriminación social.

Por otra parte, la percepción espacial de lo que me agrada o desagrada del lugar que vivo y estudio, establece su capacidad para reconocer e identificar lugares de vida cotidiana.En estas actividades de Talleres Pedagógicos se selecciona una muestra de 20 escolares de 8 a 10 años que cursan III y IV nivel de formación básica, son elegidos considerando la edad promedio de los alumnos del establecimiento y por contenidos afines tratados en aula, por sus respectivos profesores. En el gráfico $\mathrm{N}^{\mathrm{o}} 2$ adjunto se presenta porcentualmente esta distribución y el gráfico $\mathrm{N}^{\mathrm{o}} 3$ la distribución por sexo. 


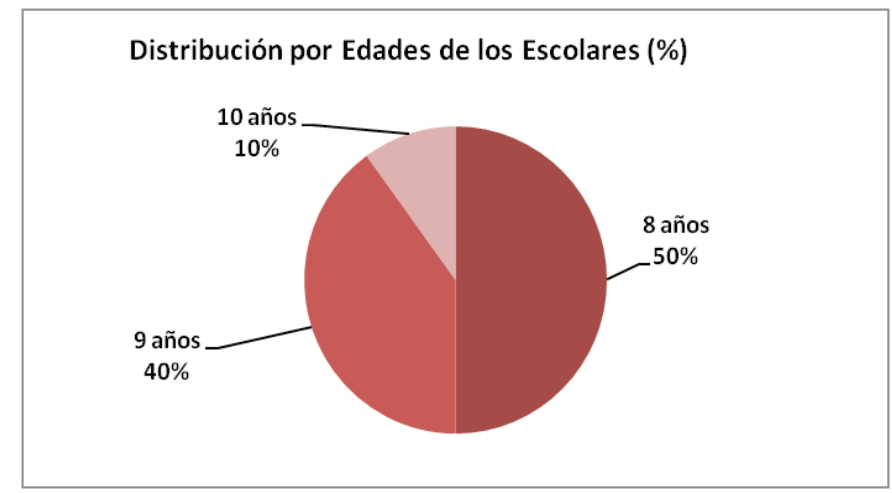

Gráfico $\mathrm{N}^{\mathrm{o}}$ 2.Distribución por edades de los escolares.

Fuente: Elaboración propia; 2013.

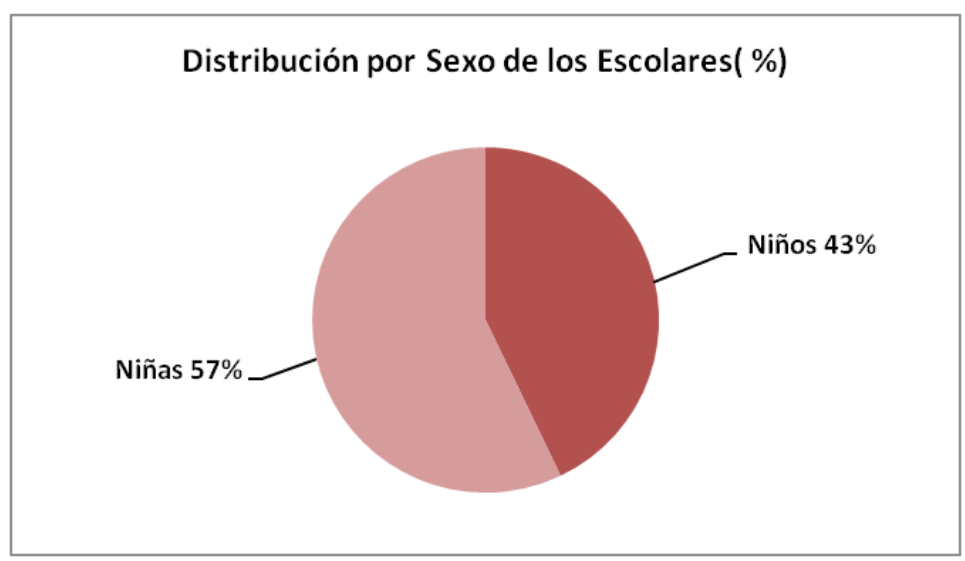

Grafico $\mathrm{N}^{\circ}$ 3. Distribución por sexo de los escolares. Fuente: Elaboración propia; 2013.

\section{INSTRUMENTOS APLICADOS}

La aplicación de los Talleres en aula se inicia con una motivación acerca de lo que es la Identidad y Percepción Personal. Se expresan estos conceptos mediante dibujos y palabras diseñadas en la pizarra con la activa intervención de los alumnos y alumnas. Por ejemplo, se realiza la conocida metáfora del espejo. "El objeto que devuelve el espejo es la imagen de sí mismo, mediante esta se afianza la Identidadque ayuda a que otros nos conozcan y reconozcan". "Si me miro en un espejo me gusta o no me gusta lo que veo físicamente; luego profundizo en atributos, cualidades, valores, habilidades personales".

Se diseñaron para estos primeros talleres dos actividades, la primera actividad se realizó en tres etapas, utilizando como instrumento tres fichas pedagógicas, en ellas se expresan los siguientes contenidos:

- Como me veo yo ...físicamente y atributos/ cualidades

- Como veo a .......( Elige la persona libremente) 
- Como veo mi paisaje/ lugar geográfico

Se dan las indicaciones para el diseño de los dibujos y para los rótulos o palabras pertinentes. La segunda actividad consistió en la aplicación de de un cuestionario de percepción de los lugares cotidianos que observan en su desplazamiento escolar diario.

\section{PRESENTACIÓN RESUMIDA DE RESULTADOS.}

Los resultados y conclusiones de la primera actividad se sintetizan en lo siguiente:

\section{Primera Actividad de Taller: IDENTIDAD}

\section{Ficha Pedagógica $N^{\circ} 1$}

Objetivo: ¿Cómo me veo yo físicamente?

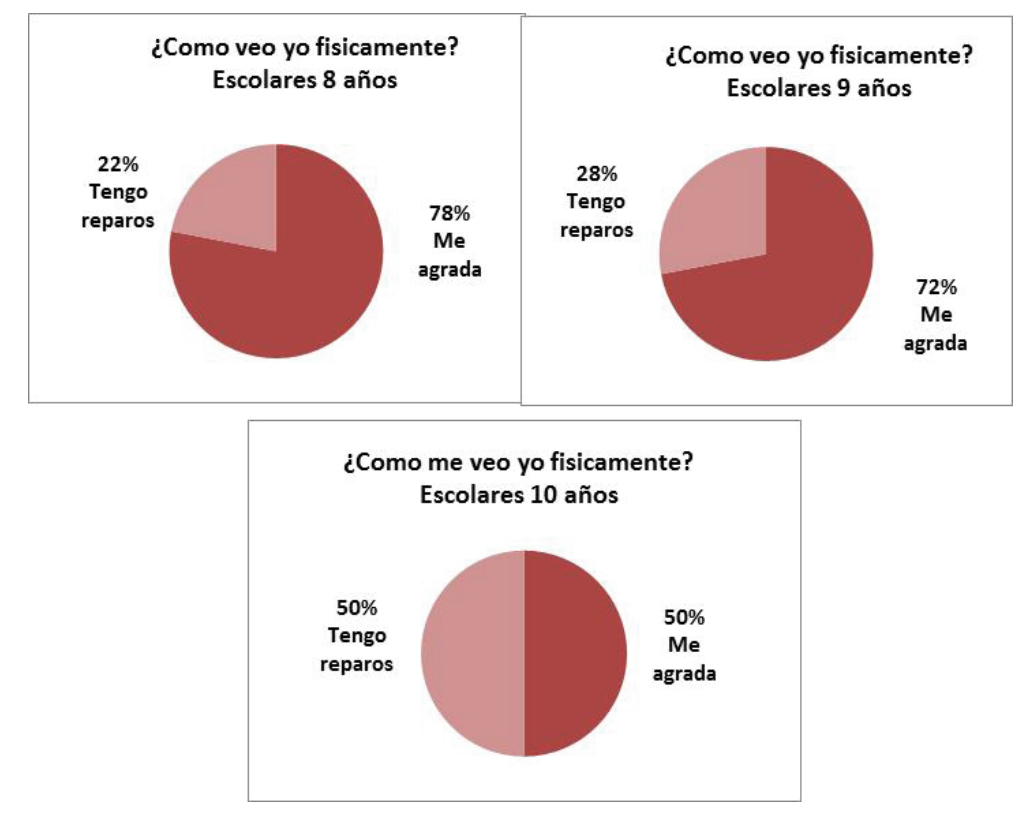

Gráfico $\mathrm{N}^{\mathrm{0}} 4$. ¿Cómo me veo yo físicamente? (\%) por edades. Fuente: Elaboracion Propia; 2013. 
B) Objetivo: ¿Cómo me veo yo? Atributos Positivos y Negativos

\begin{tabular}{|c|c|c|}
\hline Edades & Positivos & Negativos \\
\hline 8años & $\begin{array}{c}\text { Amigable, Respetuoso, Responsable con las } \\
\text { tareas }\end{array}$ & $\begin{array}{c}\text { Sensible a las burlas, Temeroso. } \\
\text { Desorientado }\end{array}$ \\
\hline 9 años & $\begin{array}{c}\text { Sociable, Planificador de actividades, Buenas } \\
\text { relaciones con los padres }\end{array}$ & Burlón, A veces flojo, Inquieto \\
\hline 10 años & $\begin{array}{c}\text { Independiente, Orgullo por sus padres, Buen } \\
\text { sentido del humor }\end{array}$ & $\begin{array}{c}\text { Carácter a veces difícil; } \\
\text { Egoísta en ocasiones. Desconfiado }\end{array}$ \\
\hline
\end{tabular}

Tabla $\mathrm{N}^{\mathrm{o}} 3$. Atributos positivos y negativos escritos. ¿Cómo me veo yo? Elaboración Propia; 2013.

\section{Comentario.}

Del gráfico $\mathrm{N}^{\mathrm{o}} 4$ se infiere que no existen grandes diferencias ante el contenido presentado para los tres grupos de de edades; físicamente la mayor parte de la muestra escolar le agrada su físico tanto niñas como niños mirado desde su yo; los reparos son menores y se cita por ejemplo que no gustan: Orejas, Narices, Pies, entre los nombrados. No hubo ningún caso de desagrado total por su aspecto físico.

Entre los atributos/ cualidades se presentan en la Tabla $N^{\circ} 3$ los más citados para los tres grupos de edades corresponden a las normales diferencias existentes para estas edades. Los tributos nombrados se vinculan estrechamente a los promedios estandarizados por los diversos estudios psicológicos para los grupos etarios correspondientes, por lo tanto, las respuestas tienen validez para el proceso de crecimiento y desarrollo que viven los niños y niñas. Cabe señalar que las palabras escritas en el texto, se han adecuado a la acción o valoración expresada por ellos mismos. 


\section{Ficha Pedagógica $\mathbf{N}^{\circ} 2$}

Objetivo: ¿Cómo me veo yo a .....?

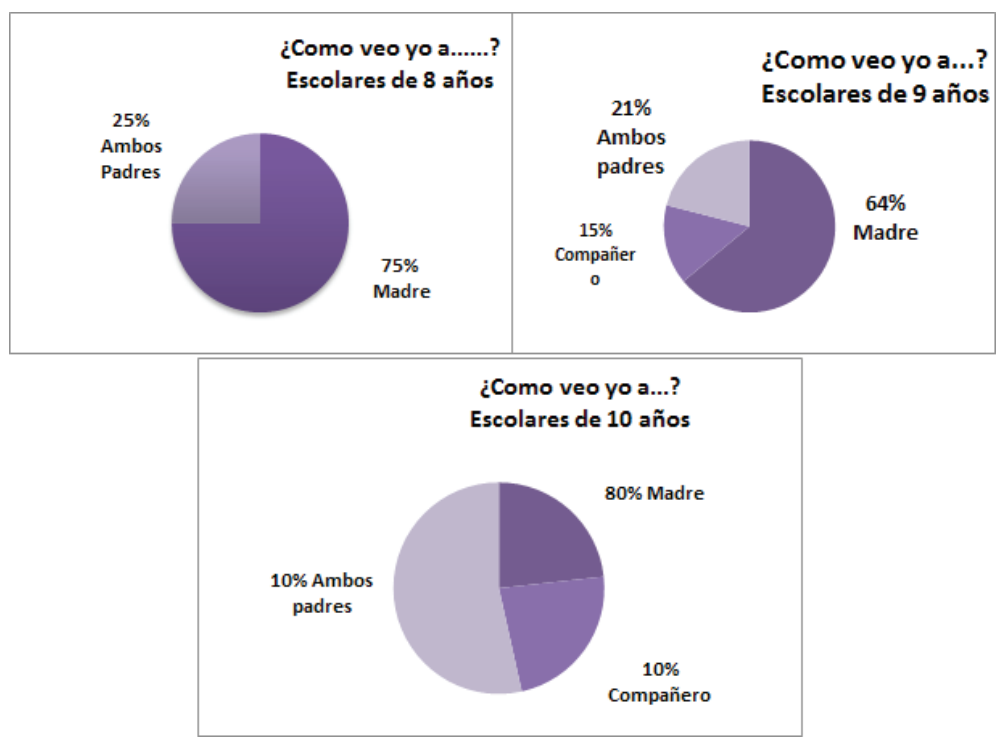

Gráfico $\mathrm{N}^{\circ}$ 5. Imágenes de Personas elegidas por los escolares según edades. Elaboración Propia; 2013.

\section{Comentario.}

Tal como se aprecia en el Gráfico $\mathrm{N}^{\circ} 5$ existe la tendencia de preferir en los tres grupos etarios la imagen de la madre o a la de ambos padres como objetos referenciales de sus percepciones y opiniones mentales; en un $96 \%$ la imagen de la madre es perfecta. Anotan que no detectan aspectos negativos en ella y les gusta tal como es, destacan su apoyo y amor. Ambos padre se citan, destacando la admiración y cariño por ellos al padre por su trabajo y dedicación al hogar. Por otra parte, un grupo más reducido elige a sus compañeros de estudio destacando su amistad y solidaridad. No se citan defectos para los elegidos.

\section{Ficha Pedagógica No 3.}

Objetivo: ¿Cómo veo mi lugar geográfico cotidiano?

En esta fase se pide a los escolares que dibujen los elementos del Paisaje Geográficoque recorren diariamente, expresando aquellos que espontáneamente surjan de su mente.Las monitoras dan ejemplos e indicaciones entre otras, hacer énfasis en que no se miden habilidades para dibujar, la expresión gráfica permite croquis, trazos, pinceladas o similares y agregan palabras.Si bien se dan indicaciones, los escolares muestran cierto temor de hacer sus dibujos, no obstante reiterando las motivaciones se dedican con entusiasmo a expresarse mediante trazos y croquis. 
A continuación se presentan algunos diseños que reflejan sus manifestaciones mentales.

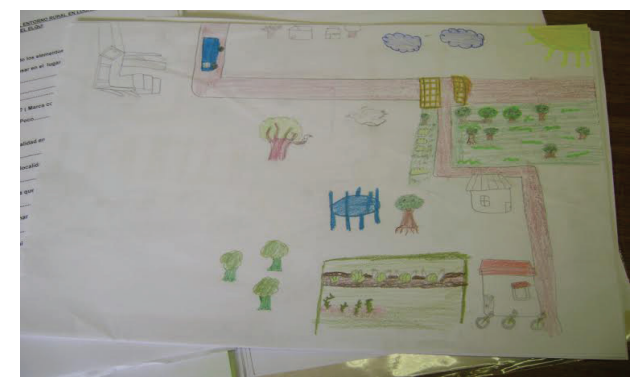

Imagen $\mathrm{N}^{\circ} 1$

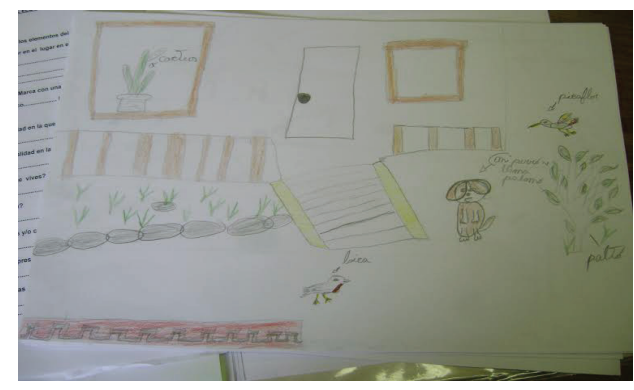

Imagen $\mathrm{N}^{\mathrm{o}} 3$

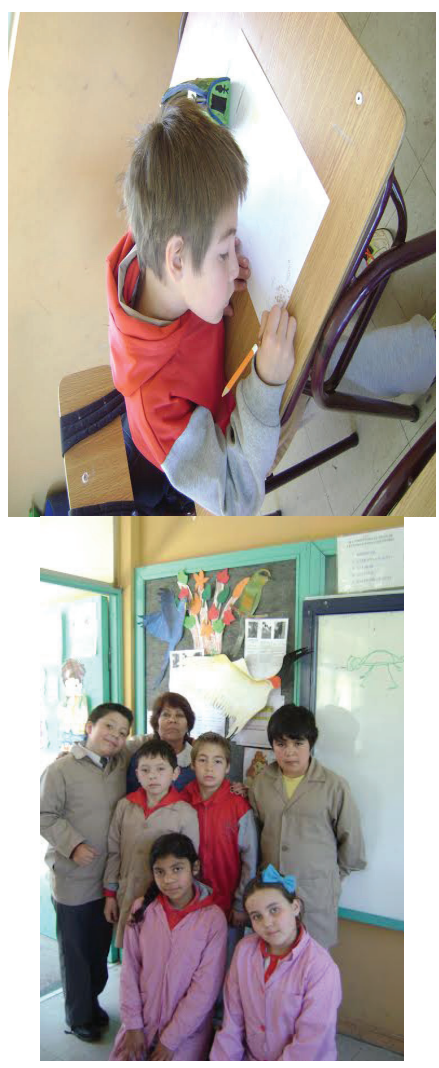

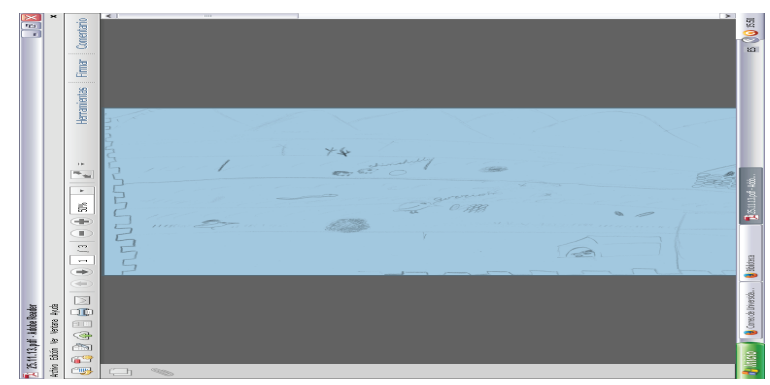

Imagen $\mathrm{N}^{\circ} 2$

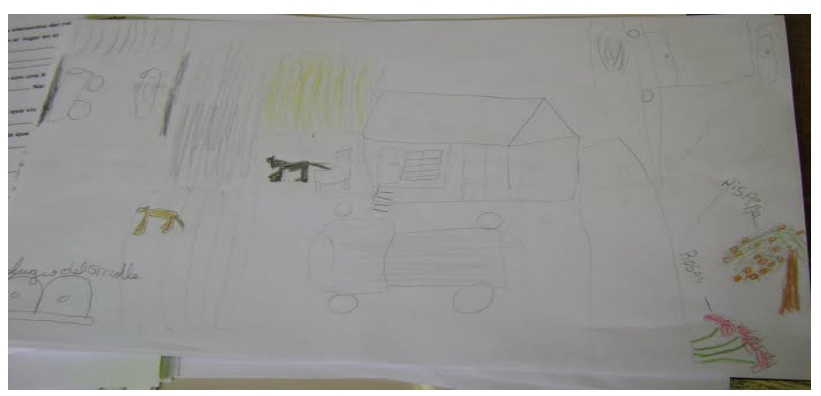

Imagen $\mathrm{N}^{\mathrm{o}} 4$
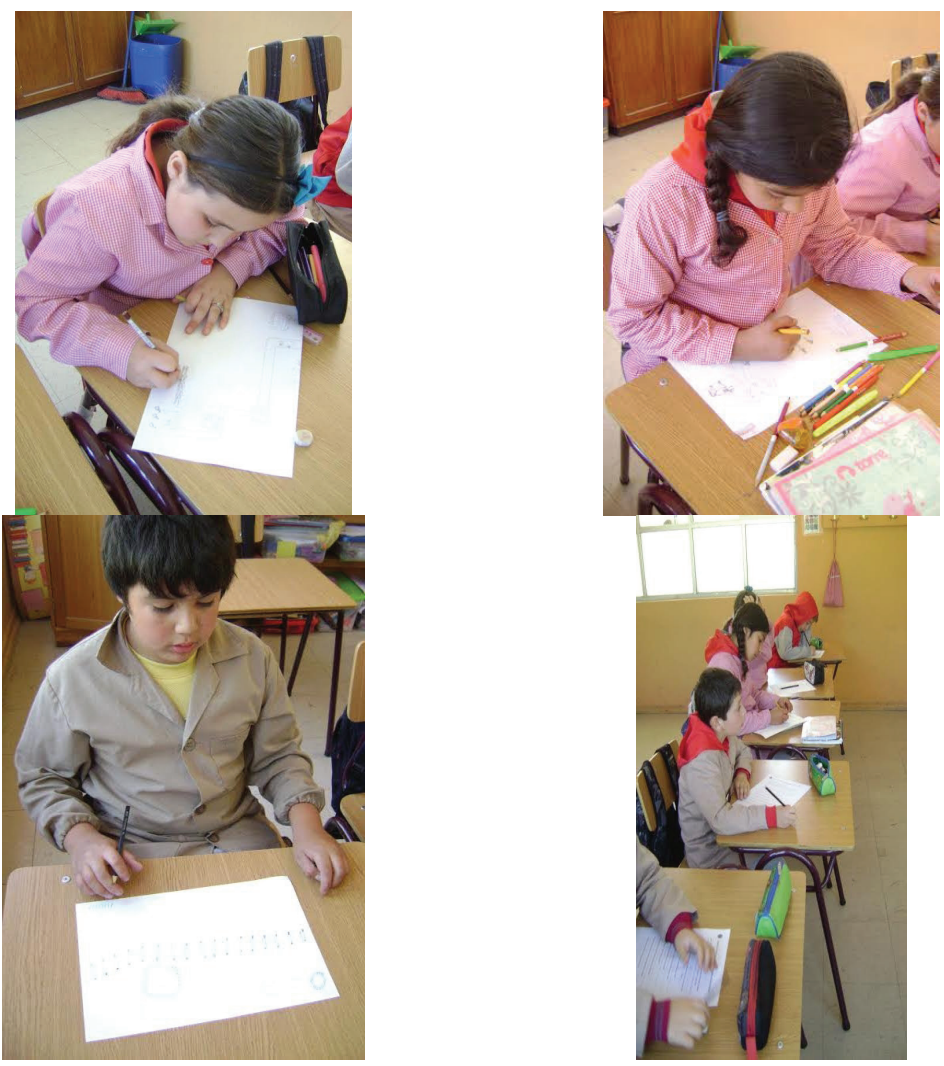

Figura. 3. Escolares en Taller, IV año Básico 


\section{Comentario:}

- Se han seleccionado cuatros representaciones mentales de escolares de 10 y 9 años.Tabulando e Interpretando las imágenes se establece que:

- El foco de interés es la casa, la mayor parte demuestra su cariño al hogar y a su familia.(Ver Imágenes)

- La vegetación local existente en el paisaje geográfico aparece con cierta dispersión característica propia de estos espacios del semi -árido chileno.

- Dibujan por ejemplo cactus y paltos propios del valle.

- Demuestran su afecto por la fauna local especialmente aves y principalmente por sus perros mascotas, especie animal que forma parte del paisaje.

- El río es otra imagen que se reitera en las representaciones espaciales de estas y de otras imágenes diseñadas.

- Entre los elementos no propios de la naturaleza, predomina la imagen del puente que da acceso al pueblo de E1 Molle desde la ruta 41 y que es atravesado día a día.

- De igual manera se dibuja la antigua y ya no existente línea del ferrocarril Coquimbo Rivadavia (Tren Elquino); el tren tenía estaciones de detención en todos los poblados a lo largo del valle, es muy recordado por generaciones de antepasados de los niños y niñas escolares que transmiten añoranzas y testimonios de como era la vida en torno a la línea férrea a sus posteriores generaciones.

- Otro elemento que se reitera es la imagen del Sol; el cielo del Valle elquino es uno de los más claros y luminosos del país y del mundo; por ello, la localización de grandes observatorios astronómicos.

\section{Segunda Actividad:}

Aplicación de Cuestionario: Percepciones del Lugar Geográfico

Se presentan algunos resultados interesantes para los objetivos propuestos del Taller y que se expresan en \% graficando lo más dibujado o rotulado, previa tabulación de estos. 


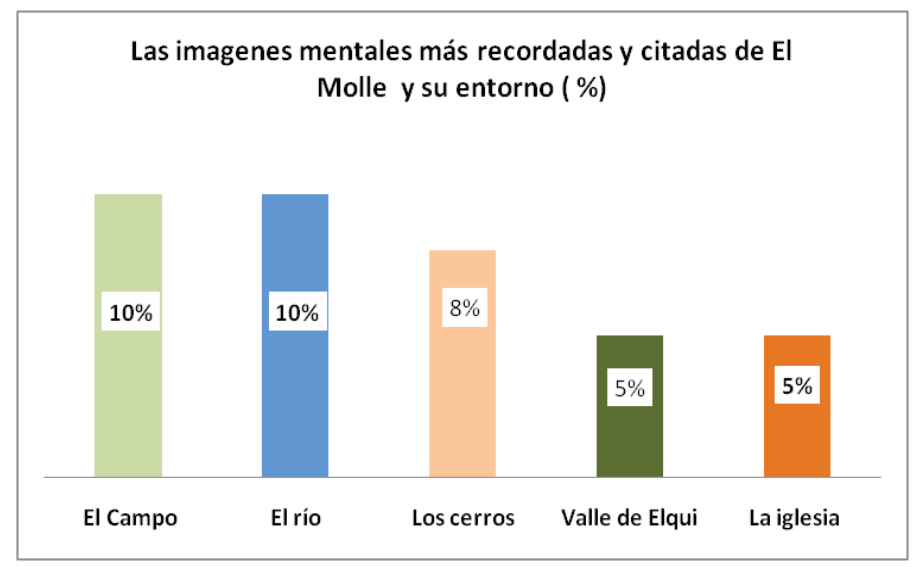

Grafico $\mathrm{N}^{\circ} 6$. Las imágenes mentales más recordadas y citadas.

Fuente: Elaboración propia, 2013.

\section{Comentario:}

Tal como se demuestra en el grafico $\mathrm{N}^{\circ} 6$ ante un ante la pregunta ¿Que imágenes recuerda de los lugares vividos al cerrar los ojos? Las respuestas priorizadas en primer y segundo lugar benefician al Campo y al río Elqui (elementos propios de paisaje físico del área, como también los cerros que circundan el valle del río) algunos (8\%) citan a la iglesia parroquial, atractivo turístico del pueblo de El Molle.

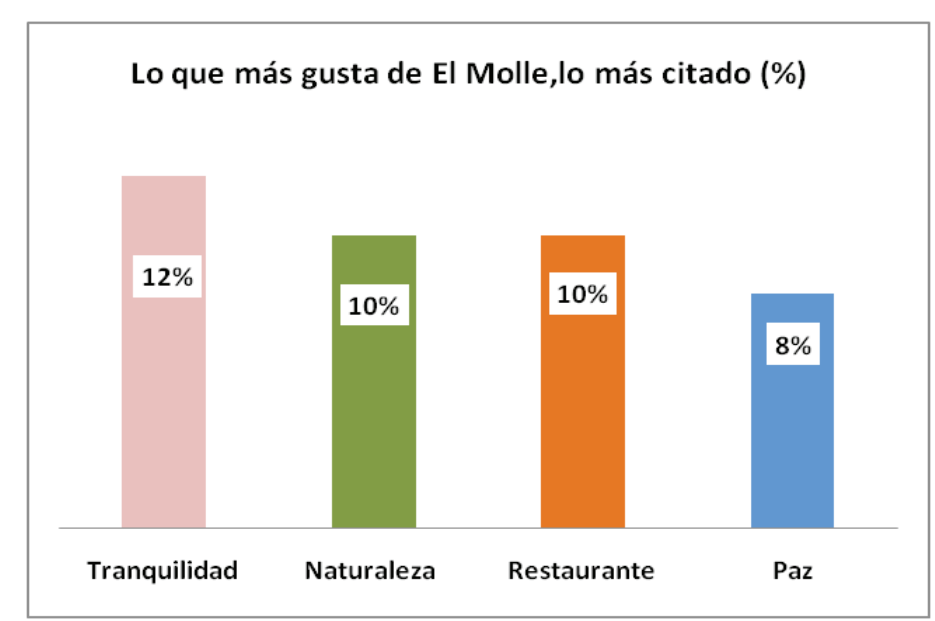

Grafico $\mathrm{N}^{\circ}$ 7. Lo que más gusta de E1 Molle y su entorno.

Fuente: Elaboración propia,2013

\section{Comentario:}

Es interesante considerar que los escolares de cortos años estiman y valoran la tranquilidad o paz que encuentran en sus pueblitos; no les agrada el ambiente de la ciudad, el 83\% viaja algunos fines de semana a la capital regional, no obstante, aunque se divierten, no les gustaría vivir en ella u otra 
ciudad grande. Por otra parte, reconocen la belleza del paisaje natural local y señalan que el Valle del Elqui es lo más lindo de la región de Coquimbo( 100\%).

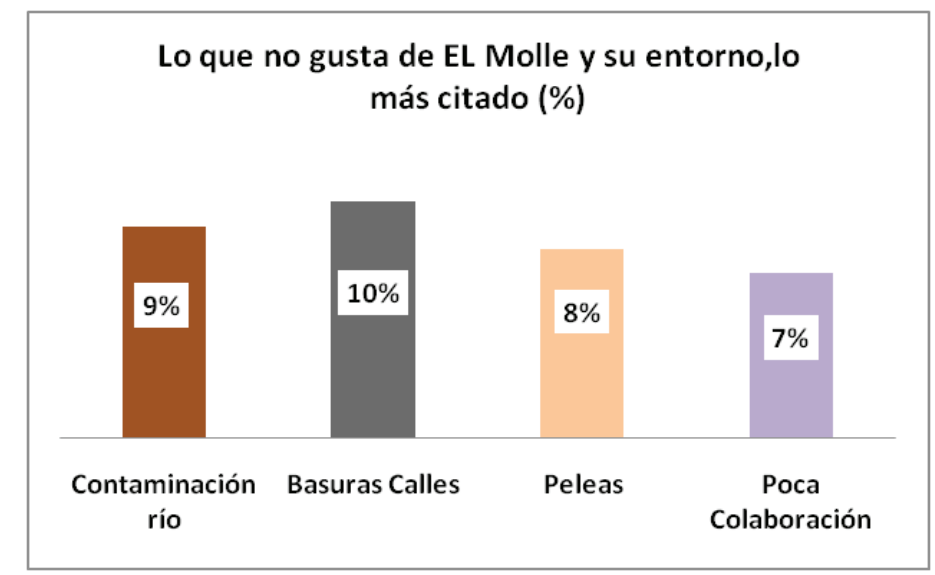

Grafico No 8 . Lo que NO gusta de El Molle y su entorno. Fuente: Elaboración propia, 2013.

\section{Comentario:}

Es importante destacar el conocimiento del paisaje y la conciencia por la preservación del medio ambiente que demuestran los escolares. Desagradan los basurales en calles y también se cita la existencia de estos deshechos en la ruta diaria hacia sus pueblos de residencia. Otra preocupación es la contaminación del río Elqui, producto de residuos domésticos e industriales locales. Se nombra en menor \% las peleas entre pobladores, causadas generalmente por consumo de alcohol; más común este comportamiento para pueblos aledaños a El Molle.

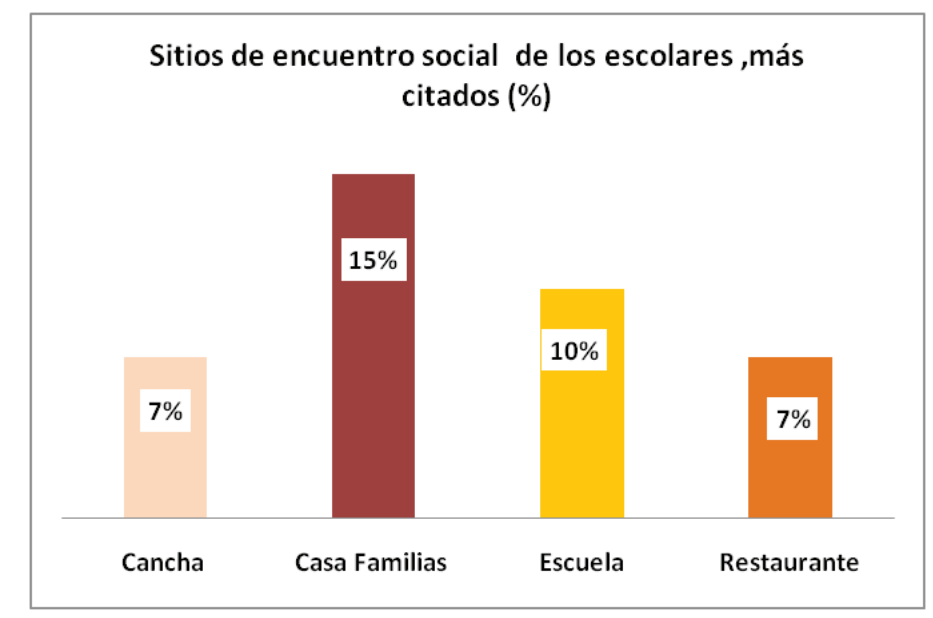

Grafico $\mathrm{N}^{\circ}$ 9. Sitios de encuentro social en E1 Molle. Fuente: Elaboración propia, 2013.

\section{Comentario:}

Es notable el valor que se otorga al hogar y al concepto de convivencia familiar, el 15\% nombró lo entretenido que era reunirse en sus casas con familiares y amigos de la escuela, principalmente los días festivos. De igual modo, la escuela es otro centro de actividades sociales, como eventos cul- 
turales y deportivos; en menor medida se cita al restaurante E1 Refugio de E1 Molle que dispone de diversos servicios como piscina y juegos y la cancha de fútbol como sitio de encuentro social.

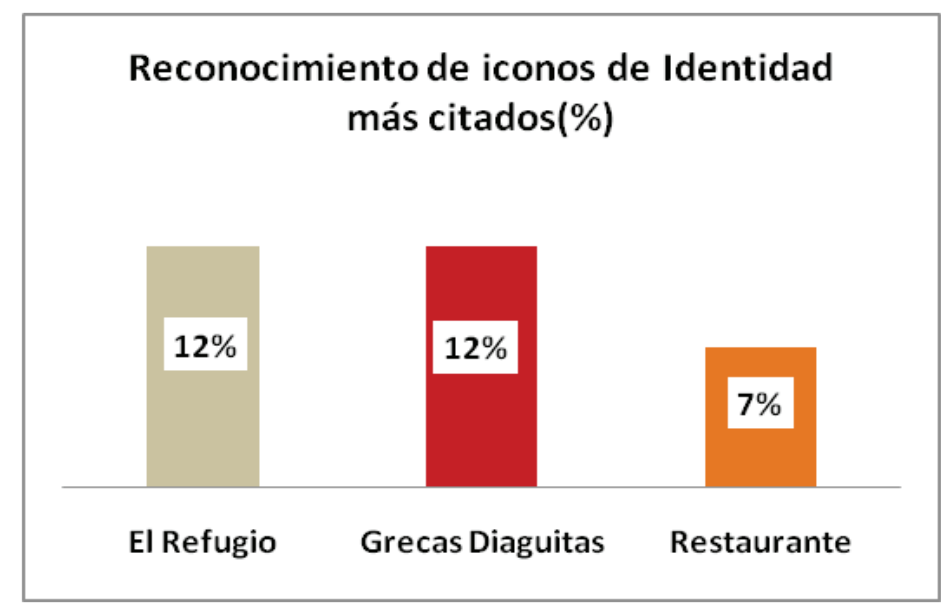

Gráfico No 10. Reconocimiento de Iconos de Identidad local.

Fuente: Elaboración propia, 2013.

\section{Comentario:}

Al preguntarse por si la localidad se identifica con un determinado icono el $12 \%$ y $7 \%$ de los dibujos muestra al Restaurante y Cabañas El Refugio ( algunos trazan el diseño del restaurante y otros el de Refugio, como se observa en el grafico $\mathrm{N}^{\circ} 8$, la referencia es la misma con nombre distinto).Este atractivo centro es reconocido por turistas regionales, nacionales y extranjeros, principalmente por la panorámica que se tiene del valle elquino y por la atención de sus variados servicios gastronómicos y recreativos. Por otra parte, otro icono representados son las grecas diaguitas que recuerdan históricamente al pueblo que ocupó parte del valle, como así el topónimo de El Molle que recuerda al pueblo agroalfararero prehispánico del norte chileno (s.III AC) en Cornelly(1938.).

\section{CONCLUSIONES}

En primer lugar las actividades del Taller Pedagógico Identidad y Percepción Geográfica han sido recibidas con gran entusiasmo de los escolares participantes, señalando que a sus cortos años es difícil encontrar sitios y oportunidades donde poder expresarse libremente acerca de lo perciben de su entorno familiar y del medio geográfico que día a día viven.

Los resultados de las representaciones mentales/dibujos obtenidos a través de de tabulaciones y las respectivas interpretaciones, se han estimado coherentes con las edades escolares y con el grado de conocimientos adquiridos en el aula y por el aporte individual del grupo familiar de su entorno.

Como se ha señalado en los comentarios las imágenes de madre y padre son cercanas, respetadas y admiradas, comportamiento ligado a un medio local rural, de pequeños caseríos y población disminuida. Realizando actividades de talleres pedagógicos en establecimientos urbanos los escolares se han manifestado con representaciones mentales que difieren en percepciones personales y colectivas. 
De igual modo, se estima que el amor a la Naturaleza se desprende del medio geográfico en que viven, son observadores y conocedores de la vegetación (Cactáceas; Árboles Frutales, Flores nativas) y de la Fauna local( Aves y animales domésticos). Sus recuerdos mentales los valoran y los asimilan a su aprendizaje.

Para la Educacion Geografica y la Didáctica de la disciplina representa esta actividad un recurso en Aula, que permite desarrollar actividades destinadas al escolar, en vías de estructurar su identidad, conociéndose asi mismo y a sus pares; encaminándolos hacia un respeto en el plano de la igualdadfrente a la diversidad presente en un aula escolar.Por otra parte, sensibiliza al estudiante en la comprensión y cuidado de medioambiente en que vive; incita ala valoración del patrimonio natural y cultural,más potencia los atributos de un buen ciudadano.

Cumplidos los objetivos propuestos los resultados del Taller que se presenta una síntesis en este texto, es una herramienta de trabajo interesante para el personal docente del establecimiento; permite conocer nuevos antecedentes personales de sus alumnas y alumnos. Para algunos ha sido sorprendente la valoración de personas y del paisaje vivido que se desprenden de las imágenes mentales construidas.

\section{REFERENCIAS}

Caneto, C. (2002). Geografia de la Percepción Urbana. Buenos Aires:Edibrel. 109 p.

Capel, H. (1973.) La percepción del medio y comportamiento geográfico: Revista de Geografía. Universidad de Barcelona.Vol.VII.Barcelona.58:150

Carrasquel G y Ugarte S(2012).Pequeñas (Re)visiones ,miradas, trazos y espejos. La plástica infantil como construcción de la Identidad.Revista Creatividad y Sociedad. N ${ }^{\circ}$ XIX ; Diciembre. Barcelona, 28 páginas.

Dollfus, O.(1990).El Espacio Geográfico. Vilassa de Mar.Ed.Oikos -Tau.

Instituto Nacional de Estadísticas.(2002). XII Censo Nacional de Población y VI de Vivienda.2002.Santiago de Chile

Lowenfeld,V. \&Brittain, W(2008). Desarrollo de la capacidad intelectual y creativa. Buenos Aires: Kapeluz.

Lynch, K. (1960). The image of the city. Cambridge. M. I. T. Pres.

Sensi D et al.(2002). La gestión de la multiculturalidad en la Escuela. Una propuesta de formación par el profesorado. Andalucía Acoge y UR.(Ediciones del G.I Traductología) para versión electrónica.

Souto, X(2007.) Educación Geográfica y Ciudadania. Revista Didáctica. N 9.11:32 
Varela C. (2011).Interacción de los asentamientos poblados del Valle de Elqui con la ciudad de la Serena. Recopilación de Resultados Talleres realizados por estudiantes 2009/2011. 30 páginas

Zamorano M. (1992). Geografia Urbana. San Isidro: Ceyne.

Zarate A. (1991). El Espacio Interior de la Ciudad.Madrid: Síntesis. 253p

Articulo recibido en febrero 15 de 2013 - Aprobado en marzo 30 de 2013 